\title{
O ENSINO DE FILOSOFIA EM OUTROS TERRITÓRIOS DO PENSAMENTO: CONEXÕES POSSÍVEIS
}

\author{
Mônica Sampaio da Silva ${ }^{1}$ \\ José Renato de Araújo Sousa ${ }^{2}$
}

\section{Resumo:}

Ao pensar a filosofia como criação de conceitos, a partir dos processos geofilosóficos de territorialização, desterritorialização e reterritorialização, o ensino de filosofia pautado nessa perspectiva propõe um olhar crítico e aberto a possibilidades de conexões da filosofia e seu ensino com outros territórios do pensamento, visando à construção constante da prática docente como processo inerente à individuação, ao estilo de cada professor, que se constrói a partir de sua formação, perspectiva filosófica e experiências vivenciadas em sala de aula. Nesse sentido, propõe-se a pensar, partindo da perspectiva de Gilles Deleuze e Félix Guattari (2010), a seguinte problemática: É possível criar conexões entre o ensino de filosofia, enquanto território existencial, com outros territórios do pensamento? Partindo desses pensadores e de alguns de seus comentadores, tem-se o objetivo de investigar a existência da possibilidade de conexões entre a prática do professor de filosofia com outros territórios do pensamento. A metodologia adotada é de uma pesquisa bibliográfica, calcada na leitura de pensadores tais como Deleuze e Guattari (2010), Cerletti (2009), Machado (1990), entre outros. A partir do contexto vivido com a chegada da pandemia do coronavírus - Covid-19, deparamo-nos com a necessidade de reorganizar o convívio social. Nesse contexto, também se encontra o professor, que precisou reinventar sua prática docente para ceder lugar a uma nova maneira de trabalhar filosofia com os estudantes. Assim sendo, neste estudo demonstramos ser possível criar conexões entre o ensino de filosofia e outros territórios do pensamento, sendo essa uma possibilidade para que o professor possa dar novos rumos à sua práxis em sala de aula.

Palavras-chave: criação conceitual; geofilosofia; território; ensino de filosofia.

\section{PHILOSOPHY TEACHING IN OTHER TERRITORIES OF THOUGHT: POSSIBLE CONNECTIONS}

\begin{abstract}
:
When thinking of philosophy as the creation of concepts based on the geophilosophical processes of territorialization, deterritorialization and reterritorialization and the teaching of philosophy based on this perspective, a critical look is and open to the possibilities of connections between philosophy and its teaching with other territories of thought which aims at the constant construction of teaching practice as a process inherent to individuation, in the style of each teacher that is built from his training, philosophical perspective and experience lived in the classroom. Thus, it proposes to think, starting from the perspective of Gilles Deleuze and Félix Guattari (2010), the following problem: is it possible to create connections between the teaching of philosophy as an existential territory with other territories of thought? Starting from these thinkers and some of their commentators, we aim to investigate the existence of the possibility of connections between the philosophy professor's practice with other territories of thought. The methodology adopted is bibliographic research with the reading of thinkers such as Deleuze and Guattari (2010), Cerletti (2009), Machado (1990), among others. From the context experienced with the arrival of the coronavirus pandemic - Covid-19, we are faced with the need to reorganize social life. In this context, there is also the teacher, who had to reinvent his teaching practice to give way to a new way of working philosophy with students. Therefore, in this study we demonstrate that it is possible to create connections between the teaching of philosophy and other territories of thought, which is a possibility for the teacher to give new directions to his praxis in the classroom.
\end{abstract}

Keywords: conceptual creation; geophilosophy; territory; philosophy teaching.

1 Mestre em filosofia - PROF-FILO/UFPI. Especialista em Ensino de Filosofia no Ensino Médio - UESPI e Graduada em Filosofia - UFPI. monicasampaio79@gmail.com

2 Professor Doutor do programa de Pós-Graduação em Filosofia da UFPI. renatocacto@ hotmail.com 


\section{Introdução}

O pensamento desenvolvido pelos franceses Gilles Deleuze e Félix Guattari (2010) inaugurou uma nova perspectiva de filosofia - como sendo "a arte de criar conceitos", opondose à filosofia clássica - como uma filosofia que pensa a partir de pressupostos e postulados. Esses pensadores também reconhecem o poder de criação de outros territórios do saber: da arte e da ciência. Contudo, estes territórios não criam conceitos. Criam agregados sensíveis e funções, respectivamente. A filosofia, a arte e a ciências são criadores, mas cada um com suas especificidades. Deleuze e Guattari (2010) se interessam pela conexão entre os territórios filosófico, artístico e científico, buscando os ecos que há entre eles.

Deleuze possui um estilo filosófico próprio e tem como marca de seu estilo compor os conceitos numa teia de relações; todos os conceitos criados por ele se conectam uns nos outros, fazendo um rizoma. O pensamento filosófico deleuziano é rizomático. Uma das maneiras de criar conceitos que compõem o pensamento deleuziano é criá-los a partir dos movimentos da geofilosofia. Deleuze, além de criar conceitos que vêm de dentro do território filosófico, desterritorializa-se para outros territórios, em busca de elementos não conceituais, que fazem conexão com seu sistema de relação conceitual e com seu plano de imanência, criando, desse modo, novos conceitos.

Entendido dessa forma:

Pensar a exterioridade da filosofia é estabelecer ecos, ressonâncias, conexões, articulações, agenciamentos, convergências entre elementos não-conceituais dos outros saberes [...] que, integrados ao discurso filosófico, são transformados em conceitos. (Machado, 1990, p. 5-6).

Ao compreender essa relação de exterioridade da filosofia, pode-se fazer um deslocamento desse entendimento à questão do ensino de filosofia, que tem a criação de conceitos como perspectiva. Deve-se pensar também na exterioridade desse ensino e sua relação com outros territórios do saber. Se o pensamento filosófico, nessa perspectiva, possui relação com o que está fora, o ensino de filosofia também admite essa relação. É nesse sentido que se formulou a seguinte questão: É possível criar conexões entre o ensino de filosofia, enquanto território existencial, com outros territórios do pensamento?

Pensamos que há sim a possibilidade de conexões entre o ensino de filosofia e outros territórios do pensamento, no intuito de criar composições possíveis do estilo filosófico do professor de filosofia como individuação inerente à prática docente. Se a filosofia é tomada como ato criativo, a prática docente, como uma questão de estilo próprio, também deve ser

\begin{tabular}{|l|l|l|l|l|}
\hline Gevista Dialectus & Ano 9 & n. 20 & Outubro - Novembro 2020 & p. 100-111 \\
\hline
\end{tabular}


criada, e isso pode ser construído a partir de processos de territorialização (a partir do próprio território, no caso, a filosofia), desterritorialização (saída do território da filosofia para outros territórios) e reterritorialização (retorno ao território) de suas práticas, no intuito de criar seu próprio estilo docente, como uma individuação.

\section{A criação conceitual a partir dos processos de territorialização, desterritorialização e reterritorialização}

Deleuze, em $O$ que é a filosofia? (2010, p. 105-106), afirma que "os filósofos são estrangeiros, mas a filosofia é grega". O que ele quis dizer com isso? Ao fazer tal afirmação, entendemos que ele quis dizer que a filosofia nasceu na Grécia, ou seja, tem origem grega, e que todo filósofo, ao fazer filosofia, utiliza a herança ou as características gregas no seu modo de filosofar. A terra da filosofia é a Grécia, e o filósofo é um estrangeiro, que sai do seu território para movimentar o pensamento, entrando em agenciamentos ${ }^{3}$, que se conectam a outros agenciamentos, constituindo-se, assim, movimentos de desterritorialização absoluta.

Ele sai do território - esse é percorrido por movimentos de desterritorialização relativa em que os elementos heterogêneos de agenciamento, em alguns casos, adquirem independência suficiente para formar uma desterritorialização absoluta. Há formação de novos agenciamentos, há movimentos, componentes de passagem nos agenciamentos territoriais. As forças de desterritorialização trabalham o território, fazendo passar agenciamentos territoriais a outros agenciamentos.

Um agenciamento comporta dois segmentos: um de conteúdo, outro de expressão. O primeiro, é agenciamento maquínico de corpos, de ações e de paixões, mistura de corpos reagindo uns sobre os outros; e o segundo, é agenciamento coletivo de enunciação, de atos e de enunciados, transformações incorpóreas atribuindo-se aos corpos. Na visão de Deleuze e Guattari (1997, p. 52), um agenciamento "se define por uma latitude e uma longitude, por velocidades e afectos, independentemente das formas e dos sujeitos que pertencem tão somente a outro plano". Isso porque, no plano de imanência, os agenciamentos comportam hecceidades, que não têm começo nem fim, mas um meio, são rizomas. Os indivíduos, que são latitude e longitude, possuem uma individuação, ou uma hecceidade, em "que param de ser sujeitos para devir acontecimentos em agenciamentos" (Deleuze e Guattari, 1997, p. 52).

3 Os agenciamentos, para Deleuze, são entendidos como aquilo que se relaciona, se conecta a algo, que faz ressonância, ligação com algo, são componentes de passagem.

\begin{tabular}{|l|l|l|l|l|}
\hline Govista Dialectus & Ano 9 & n. 20 & Outubro - Novembro 2020 & p. 100 - 111 \\
\hline
\end{tabular}


Segundo os autores citados (1997, p. 53), há agenciamentos que comportam segmentos de conteúdo e de expressão, "pois o plano de consistência só tem por conteúdo hecceidades, ele tem também toda uma semiótica particular que lhe serve de expressão. Plano de conteúdo e plano de expressão”. No plano de consistência ou imanência, há hecceidades de agenciamentos - corpo como longitude e latitude, e hecceidades de interagenciamentos - linhas que se cruzam entre longitude e latitude.

Existe uma composição, uma semiótica que serve ao segmento de expressão de um agenciamento; essa semiótica é "composta de nomes próprios, de verbos no infinitivo e de artigos ou pronomes indefinidos" (Deleuze e Guattari, 1997, p. 53). Como exemplos, podemos citar um devir-animal, um devir-criança, um devir-imperceptível. O tempo do verbo no infinitivo é do acontecimento ou do devir, que se opõe ao tempo cronológico.

Deleuze e Guattari, em "Mil Platôs" - Vol. 4 (1997), fazem uma crítica à psicanálise, afirmando que essa quer, a todo custo, interpretar os indefinidos como um definido, um possessivo escondido por trás do indefinido. Já esses autores defendem o contrário. Pensam o indefinido como um agenciamento coletivo, como um individuante, e não como uma determinação de subjetividade como condição de toda enunciação. O agenciamento coletivo de enunciação relaciona-se com o manejo do indefinido como individuante em um coletivo.

Um agenciamento tem, ao mesmo tempo, lados territoriais ou reterritorializados. Esses se referem ao campo de experiência, em que se elaboram o plano de imanência; é máquina abstrata. Um agenciamento é máquina abstrata num plano de imanência porque esse implica uma destratificação de formas, funções e de sujeitos do plano transcendente para extrair afectos, agenciamentos, por isso que não para de reconstituir-se um no outro, de extrair-se um do outro, implicando, assim, movimentos de desterritorialização - saída do território dado - que o plano transcendente sempre tenta cortar as linhas de fuga, ou seja, reterritorializar-se, interromper os movimentos de desterritorialização. É abstrata porque não se sabe, de antemão, quando acontece a passagem de um plano ao outro.

A Grécia é a terra da filosofia, e o filósofo é aquele que sai do território - seu modo de filosofar - para reterritorializar-se sobre a terra. A filosofia grega possui três traços, são eles: a imanência, a amizade e a opinião ou conversação. Quando o filósofo reterritorializa, ele se apropria, de algum modo, desses três traços gregos. A terra e o território, segundo Deleuze e Guattari (1997), estão sempre em defasagem, um em relação ao outro; a primeira, como ponto intenso em profundidade, como razão de ser; e a segunda, como condição de conhecimento, como saber. É essa defasagem que faz com que o agenciamento viva o território, mas como

\begin{tabular}{|l|l|l|l|l|}
\hline Gevista Dialectus & Ano 9 & n. 20 & Outubro - Novembro 2020 & p. $100-111$ \\
\hline
\end{tabular}


território perdido, desterritorializado. O essencial na filosofia está em tornar o pensamento móvel, movimentá-lo, e não tomá-lo como juízo sintético. O essencial está nas forças e intensidades desses movimentos, e não nas formas e matérias.

Na filosofia, aparece um princípio de razão contingente, mas os gregos captaram a relação do objeto com o sujeito como contemplação, e é nesse sentido que Deleuze e Guattari (2010) afirmam que o sujeito e o objeto oferecem uma má aproximação do pensamento: pensar se faz na relação entre o território e a terra. E esses são dois componentes indiscerníveis: desterritorialização (do território à terra) e reterritorialização (da terra ao território).

Refere-se, a reterritorialização, às tentativas, a todo custo, de retorno ao plano transcendente, das linhas molares ${ }^{4}$ e ao território. A memória ou a lembrança tem a função de reterritorializar, ela faz voltar-se ao território, por isso o "devir é uma antimemória" (Deleuze e Guattari, 1997, p. 96), porque no devir a memória é molecular, pois não integra um sistema molar, a desterritorialização comporta componentes moleculares.

Ainda em "Mil Platôs" - vol. 4 (1997), esses filósofos apontam que os sistemas de territorialização e de reterritorialização são sistemas pontuais - nesses sistemas a linha e a diagonal servem de coordenadas ou ligações de um ponto a outro - enquanto que os sistemas de desterritorialização, rizomático, são sistemas lineares ou multilineares, uma vez que "a linha libera-se do ponto como origem; a diagonal libera-se da vertical e da horizontal como coordenadas; da mesma forma, a transversal libera-se da diagonal como ligação localizável de um ponto a outro" (Deleuze e Guattari, 1997, p. 102). Sendo assim, é necessário que se faça funcionar, ao mesmo tempo, componentes de territorialização, desterritorialização e reterritorialização.

Já a desterritorialização pode ser de dois modos: relativa, "na medida em que concerne à relação histórica da terra com os territórios que nela se desenham"; e absoluta, "quando a terra entra no puro plano de imanência de um pensamento que absorve a terra" (Deleuze e Guattari, 2010, p. 107). Em se tratando da desterritorialização absoluta, essa sempre encontra uma maneira, sobre o plano de imanência, de tomar o lugar de uma desterritorialização relativa, pois "pensar implica aqui numa projeção do transcendente sobre o plano de imanência" (Deleuze e Guattari, 2010, p. 107). Quando a desterritorialização relativa é transcendente, o elemento transcendente deve inclinar-se para se inscrever sobre o plano de imanência. Nesse caso, "a transcendência que se projeta sobre o plano de imanência [...] o povoa de figuras"

4 As linhas molares, para Deleuze, referem-se aos sistemas binários - homem/mulher, criança/adulto etc.; arborescentes, circulares e segmentares. Sobre as linhas de segmentaridade, ver Mil Platôs vol. 3, 2012.

\begin{tabular}{|l|l|l|l|l|}
\hline Govista Dialectus & Ano 9 & n. 20 & Outubro - Novembro 2020 & p. 100 - 111 \\
\hline
\end{tabular}


(Deleuze e Guattari, 2010, p. 108). Os hexagramas e a mandala são exemplos de pensar por figuras.

Esses autores (2010) afirmam que a desterritorialização relativa, quando é transcendente, é vertical, celeste; mas quando ela se projeta sobre o plano de imanência, como espiral, a vertical celeste desce sobre a horizontal do plano de pensamento, ou seja, sobre a imanência. É nesse ponto que a desterritorialização deixa de ser relativa para ser absoluta; também é nesse ponto que se pensa por conceitos, e não mais por figuras, e isso acontece quando o pensamento deixa de projetar-se em termos para conectar-se aos conceitos, uma vez que os conceitos não se projetam, eles se conectam. Na criação conceitual, no ponto de vista de Deleuze, os conceitos entram num sistema de relação, de conexão, de conjunção para compor o pensamento.

Deleuze e Guattari (2010, p. 115) afirmam que a filosofia é uma geofilosofia, isso porque "a geografia não se contenta em fornecer uma matéria e lugares variáveis para a forma histórica". Para eles, a filosofia é devir, e o devir não é história, mas contingência. É nesse sentido que o conceito é mais geográfico que histórico, porque "nasce na história, nela recai, mas não pertence a ela. Não tem em si mesmo início e nem fim, mas somente um meio. Assim, é mais geográfico que histórico" (Deleuze e Guattari, 2010, p. 132). Criar conceitos é puro acontecimento, é puro devir sobre o plano de imanência. $\mathrm{O}$ acontecimento é contingente, e não histórico.

Esses autores não pensam a filosofia de forma linear e progressiva, mas como espaços em que há movimentos ou possibilidades de pensamento. Assim, o plano de imanência é entendido como o solo, a terra ou a fundação em que a filosofia vai criar seus conceitos.

Deleuze (1988) critica a filosofia clássica, entendida como imagem dogmática do pensamento, a fim de engendrar a sua filosofia como pensamento sem imagem. Em palestra proferida, Roberto Machado ${ }^{5}$ afirmou que Deleuze criou dois espaços antagônicos. Segundo ele (2014), Deleuze cria o espaço da filosofia como imagem dogmática do pensamento, e o espaço da filosofia como pensamento sem imagem. É nesses dois espaços que Deleuze situa a sua filosofia, e não numa dimensão histórica. Por isso que Machado (2014) afirma que sua palestra também poderia intitular-se: "A geografia deleuziana do pensamento".

Sendo assim, pode-se perceber que o pensamento filosófico deleuziano é engendrado em espaços, e não numa dimensão histórica. Por isso que Deleuze e Guattari (2010)

5 Palestra proferida por Roberto Machado, intitulada: Deleuze e a filosofia. Universidade Federal do Acre, em 2 de set. 2014. Disponível em: https://www.youtube.com/watch?v=_ttmrtL0RBA. Acesso em: 18 dez. 2019.

\begin{tabular}{|l|c|c|c|c|}
\hline Q & Ano 9 & n. 20 & Outubro - Novembro 2020 & p. $100-111$ \\
\hline
\end{tabular}


afirmam que a filosofia é uma geofilosofia. E assim sendo, os seus processos acontecem da seguinte maneira: o filósofo traça o plano de imanência, sua terra, o qual utiliza para orientarse no pensamento; a filosofia é o seu território, e a partir do seu território o filósofo pode criar seus conceitos, sem sair do seu território, ou pode sair dele (desterritorializar-se) para outros territórios e extrair elementos não-filosóficos, para então retornar ao território (reterritorializarse) ressignificando-os e, assim, criar conceitos.

Assim sendo, indagamo-nos: É possível a criação de conceitos no ensino de filosofia com os estudantes? Criar conceitos envolve o gosto filosófico. Ao longo do tempo, lidando com a história da filosofia e os conceitos criados pelos filósofos, é que se pode ousar criar conceitos. Sabe-se que não há a pretensão de transformar os estudantes de filosofia em filósofos, a não ser numa graduação em filosofia, e nem há o tempo necessário para tal ousadia; não é algo fácil de se alcançar, tanto por parte do professor como do estudante, mas também não é impossível. Pode ser que em algum momento, raro é claro, um/a estudante ou professor crie um conceito.

É a partir dos processos da geofilosofia que se busca investigar a existência da possibilidade de conexões entre a prática do professor de filosofia com outros territórios do pensamento, no sentido de que cada professor possui seu modo de trabalhar a filosofia em sala de aula e, desse modo, cria seu estilo próprio de ser professor, como modo singular, numa repetição autêntica, que não se assemelha e nem visa a um modelo ideal de prática a ser seguido.

Nesse sentido, a prática docente não é a simples adoção de um método para ensinar filosofia, mas a criação de um estilo próprio, que faz parte da própria individuação e que pode ser entendido como ato de criação, pois para Deleuze e Guattari (2010), o que importa é criar, é tentar fugir do modelo de identidade, da representação, da forma do Mesmo.

\section{O ensino de filosofia e as possibilidades de conexões com outros territórios do pensamento}

A partir do contexto vivido com a chegada da pandemia do coronavírus - Covid19 -, deparou-se com a necessidade de reorganizar o convívio social. Conforme orientações das instituições de saúde, as interações sociais devem ser evitadas, o que levou as pessoas a se distanciarem fisicamente, como medida de prevenção para evitar a contaminação pelo vírus. Assim sendo, surgiram novas formas de interação, deparando-se, também, com a necessidade de criar, de inventar novas formas de trabalhar. 
Nesse contexto, também se encontra o professor, que precisou se reinventar, ou seja, criar novas formas de trabalhar o conteúdo, novas metodologias diante do formato das aulas remotas. O professor foi, de certa forma, obrigado a reinventar-se, e tudo que já havia estudado e incorporado ao seu fazer docente, precisou ser repensado e ceder lugar a uma nova maneira de trabalhar a filosofia com os estudantes.

Deleuze (1988) fala que não tem como saber previamente como alguém aprende, sendo assim, não há método para aprender e, consequentemente, para ensinar, "mas um violento adestramento, uma cultura" que percorre o indivíduo. Não há método porque esse pressupõe o saber, é a manifestação do senso comum - que constitui a doxa - tendo como pressuposto "uma boa vontade como uma 'decisão premeditada' do pensador", ao passo que a cultura, que pressupõe o aprender, é involuntária, já que se passa no inconsciente, para encadear uma sensibilidade, uma memória, e depois um pensamento, que se dá, como já foi dito, por "um violento adestramento". Por isso que "é do 'aprender' e não do saber que as condições transcendentais do pensamento devem ser extraídas" (Deleuze, 1988, p. 160).

Segundo Cerletti (2009), ao se pensar o ensino de filosofia, deve-se levar em consideração a concepção de filosofia adotada pelo professor, e dependendo da concepção que se tome, influenciará sobre o sentido de ensinar filosofia. Afirma ainda que o professor deverá ser um filósofo, pois filosofará com os estudantes, a partir de sua concepção filosófica, ou da concepção adotada por ele. Sendo assim, ensina-se filosofia com enfoque numa perspectiva filosófica, desse modo, o ensino de filosofia consiste numa forma de intervenção filosófica sobre o que se ensina.

Deleuze e Guattari (2010) afirmam que o filósofo é criador, e não reflexivo; assim sendo, o professor de filosofia, em certa medida, também é um filósofo, e um filósofo criador, que deve buscar criar seus conceitos, e consequentemente, criar sua prática docente. Partindo desse entendimento sobre o ensino de filosofia, e considerando a perspectiva filosófica deleuziana da filosofia como geofilosofia - de desterritorializar-se e reterritorializar-se - há que se pensar na possibilidade de se ensinar filosofia nessas condições expostas aqui. Se a filosofia admite uma relação de exterioridade com outras formas de pensamento e cria conceitos com elementos vindos de fora do seu território, há de se pensar também o ensino de filosofia e sua relação com o que vem de fora.

Ao ensinar filosofia, nessas condições, deve-se assumir uma postura aberta ao novo, à criatividade e a possibilidades de construção do fazer docente, que sempre se encontra em

\begin{tabular}{|c|c|c|c|c|}
\hline Qevista Dialectus & Ano 9 & n. 20 & Outubro - Novembro 2020 & p. $100-111$ \\
\hline
\end{tabular}


vias de vir a ser, e não como algo engessado, ou com a passiva adoção de modelos ou métodos de se trabalhar filosofia com os estudantes.

Entendendo o ensino de filosofia como uma construção constante da prática docente e aberta a possibilidades, propõe-se um deslocamento conceitual dos processos geofilosóficos de territorialização, desterritorialização e reterritorialização, para pensar a prática docente a partir desses processos. O professor, nessa perspectiva, deve buscar as conexões possíveis dos conhecimentos do território filosófico com outros territórios, como o artístico ou o científico; pensar a filosofia a partir de elementos de outros territórios, conectando-os ao seu plano de imanência e ao problema levantado por ele e seus estudantes, pois o ensino de filosofia, nessa concepção, deve ser voltado para uma abordagem problematizadora, e não para uma abordagem reflexiva ou contemplativa.

Nessa prática pedagógica, o professor deverá encontrar conexões, ressonâncias entre o pensamento filosófico e os outros territórios do pensamento, no intuito de problematizar e provocar os estudantes a movimentarem o pensamento e a criarem possibilidades de pensar a filosofia numa perspectiva criadora e, desse modo, fugir da perspectiva da filosofia como representação do mundo, da reflexão sobre as coisas, sobre os fatos históricos e da contemplação da realidade.

De acordo com a perspectiva deleuziana, não há uma hierarquia dos saberes (entendidos como territórios), mas diferentes territórios, que são igualmente criadores. Segundo Deleuze e Guattari (2010), a filosofia, a arte e as ciências são criadoras, porém, cada uma com suas peculiaridades. A filosofia cria conceitos, a arte cria agregados sensíveis e a ciência cria funções. Esses filósofos afirmam que há relações entre esses territórios, que se dão por conexões que se fazem de uma infinidade de maneiras possíveis, e não são predeterminadas.

É nesse sentido que acreditamos que as práticas docentes são constituídas dos processos da geofilosofia, um constante territorializar-se, desterritorializar-se e reterritorializarse, como meio de criação, que favorece tais condições para a noção de filosofia como atividade criadora. É nessas práticas, enquanto docentes nômades, que saem do território da filosofia para habitar outros territórios não filosóficos, como a literatura, o cinema, a música, o teatro, entre outros, e extrair desses territórios elementos não filosóficos para criar, de forma singular, suas práticas. Dessa forma, está instaurada a função da filosofia, conforme o pensamento deleuziano, como a arte de criar conceitos.

$\mathrm{Na}$ escola, o professor encontra-se envolvido com modos/práticas de ministrar aulas, práticas essas concebidas como bons modelos a serem seguidos; ao tentar criar novos

\begin{tabular}{|l|l|l|l|l|}
\hline Gevista Dialectus & Ano 9 & n. 20 & Outubro - Novembro 2020 & p. $100-111$ \\
\hline
\end{tabular}


modos para trabalhar em sala de aula, ou seja, criar seu estilo no fazer docente, ele rompe com o instituído, para se desterritorializar, para criar linhas de fuga. E o seu fazer como professor encontra-se nesse constante deslizar entre práticas instituídas (modelos a serem seguidos) e modos inventivos de ser professor (linhas de fuga ou desterritorialização).

\section{Considerações finais}

O ensino de filosofia, numa perspectiva deleuziana, tomado como um ensino que não visa a refletir sobre as coisas, sobre os fatos históricos, muito menos contemplar a realidade, é vivenciado como ato de criação, que busca fugir do instituído, de métodos e modelos, e que está constantemente pensando e criando sua prática docente.

A prática docente encontra-se em constante devir, atualizando-se, desterritorializando-se e reterritorializando-se; porém, cada vez que volta ao território, problematiza-o, modifica-o, ressignifica-o, transforma-o e recria-se, de acordo com os elementos disponíveis, para torná-lo outro. E é nesse sentido que afirmamos que todo professor cria seu estilo próprio de ser professor, que é algo inerente e singular a cada um.

Para os filósofos franceses abordados neste estudo, a realidade é tomada como multiplicidade, como acontecimento, não se podendo prever como será uma aula; é nesse sentido que Deleuze (1988) vai contra a noção de método ou modelo preestabelecido, a realidade não está dada, é contingência. Então, como trabalhar a filosofia, se não se pode prever o que se está por vir? Ora, não se pode prever o futuro, mas se pode pensar as práticas e criar possibilidades para a sua realização.

Segundo Deleuze, em $O$ abecedário na letra $P$ de Professor (1994, p. 80), "uma aula é ensaiada. E como no teatro e nas cançonetas, há ensaios, se não tivermos ensaiado bastante, não estaremos inspirados. Uma aula quer dizer momentos de inspiração, senão não quer dizer nada". Sendo assim, o professor, ao ensaiar suas aulas e ao ministrá-las, deve achar interessante a matéria da qual fala, tem de gostar do que faz. Há todo um preparo ao planejar uma aula.

Os professores, com suas posturas nômades e fundamentados na concepção deleuziana da filosofia como geofilosofia, devem buscar constantemente desterritorializar-se e reterritorializar-se, com o intuito de provocar possíveis bons encontros, a partir dos elementos não filosóficos, para tornarem suas aulas interessantes e afastar-se da recognição. Ao caminhar por outros territórios, os professores trazem deles elementos que serão utilizados como meios 
para pensar questões filosóficas e problemas de seu tempo, conferindo à filosofia o seu destaque no currículo educacional, não a atrelando a discussões acerca de sua utilidade ou finalidade, e sim como algo interessante, que sai do patamar da "reflexão sobre", da contemplação, da tagarelice. Para Deleuze (2014), a filosofia tem que ser interessante, e o filósofo deve achar interessante aquilo que diz. É contagiar, é afetar, provocar possibilidades de bons encontros, movimentar o pensamento, é contingência, é acontecimento por vir.

Portanto, ao pensar o ensino de filosofia a partir da perspectiva deleuziana, fica claro que não há modelos ou métodos preestabelecidos para ensinar filosofia, devido à multiplicidade e contingência da realidade. Então, como trabalhar/ministrar a filosofia em sala de aula? Entende-se que há inúmeras possibilidades de criação de práticas que sempre necessitarão de ajustes, adequações e modificações, visto que a realidade é entendida como uma multiplicidade, e que se deve buscar conexões possíveis de se efetuar na criação de suas práticas e, dessa forma, suscitar a criação de possibilidades de bons encontros, que possam ser capazes de afetar os estudantes.

\section{Referências}

CERLETTI, A. O ensino de filosofia como problema filosófico. Tradução de Ingrid Müller Xavier. Belo Horizonte: Autêntica Editora, 2009. (Ensino de Filosofia).

DELEUZE, G. Conversações (1972-1990). Tradução de Peter Pál Pelbart. 3. ed. São Paulo: Editora 34, 2013. 240p. (Coleção TRANS)

. Crítica e Clínica. Tradução de Peter Páll Pelbart. São Paulo: Editora 34, 1997.

Graal, 1988 .

. Diferença e Repetição. Tradução de Luiz Orlandi e Roberto Machado. Rio de Janeiro:

Lógica do sentido. Tradução de Luiz Roberto Salinas Fortes. São Paulo: Perspectivas/Ed. da Universidade de São Paulo, 1974.

Proust e os signos. 2. ed. Tradução de Antônio Piquet e Roberto Machado. Rio de Janeiro: Forense Universitária, 2003.

DELEUZE, G.; GUATTARI, F. Mil Platôs: Capitalismo e Esquizofrenia. Tradução de Aurélio Guerra Neto e Célia Pinto Costa. São Paulo: Editora 34, 1995. Vol. 1.

Mil Platôs: Capitalismo e Esquizofrenia. Tradução de Aurélio Guerra Neto, Ana Lúcia de Oliveira, Lúcia Cláudia Leão e Suely Rolnik. São Paulo: Editora 34, 1996. Vol. 3

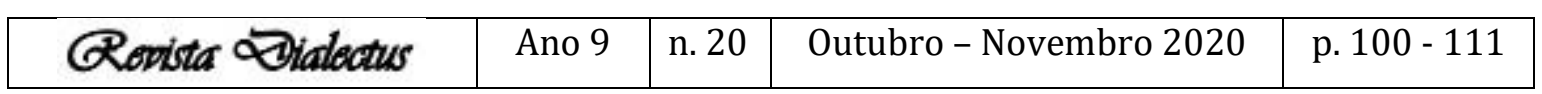


. Mil Platôs: Capitalismo e Esquizofrenia. Tradução de Suely Rolnik. São Paulo: Editora 34, 1a Edição - 1997. Vol. 4

O que é a Filosofia? 3. ed. Tradução de Bento Prado Jr. e Alberto Alonso Muñoz. São Paulo: Editora 34, 2010.

L'ABÉCÉDAIRE DE GILLES DELEUZE - versão legendada em português pela TV Escola MEC, na série Ensino Fundamental. Entrevista publicada por Claire Parnet e Pierre-André Boutang em 1994.

MACHADO, R. Deleuze e a filosofia. Universidade Federal do Acre em 02-09-2014. Palestra. Disponível em: https://www.youtube.com/watch?v=_ttmrtL0RBA. Acesso em: 18 dez. 2019.

Deleuze e a filosofia. Rio de Janeiro: Graal, 1990. 